\title{
VACCINES IN THE PREVENTION OF VIRAL PNEUMONIA
}

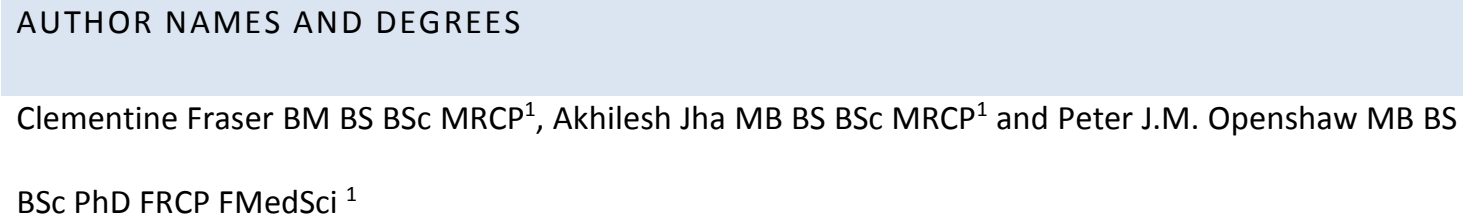

Published online as article in press on $18^{\text {th }}$ December 2016 in Clinics in Chest Medicine 
KEY POINTS

- Viral pneumonias are a major cause of disease and death across the globe.

- Vaccination is a most effective way of preventing infection, but is only available for a limited (but expanding) number of respiratory pathogens.

- Current seasonal Influenza vaccines confer insufficient protection, especially in some highrisk populations (e.g. older adults).

- Research into correlates of protection has identified new ways to develop universal influenza vaccines that induce broad and long -lasting humoral and cell-mediated responses.

- Respiratory Syncytial Virus is a common cause of viral pneumonia and a largely unrecognized killer of frail elderly persons. Many promising vaccines are under development and there are high hopes of effective vaccines in the near future.

SYNOPSIS

Pneumonia is of great global public health importance. Viral infections play both a direct and indirect part in its etiology across the globe. Influenza is a leading cause of viral pneumonia in both children and adults, and respiratory syncytial virus (RSV) is increasingly recognized as causing disease at both the extremes of age. Vaccination offers the best prospect for prevention but current influenza vaccines do not provide universal and durable protection, especially in high-risk populations and require yearly reformulation. In the future, it is to be hoped that influenza vaccines will give better and universal protection, and that new vaccines can be found for other causes of viral pneumonia. 


\section{INTRODUCTION}

Pneumonia is of huge global public health concern. Viral and bacterial pneumonias are major and leading causes of global mortality, the impact being greatest in children, the elderly and the immunodeficient and those with co-morbidities ${ }^{1-3}$. In 2015, pneumonia was estimated to cause 41.7 deaths per 100000 population ${ }^{4}$. In 2010, it is thought that there were approximately 15 million hospital admissions for severe acute lower respiratory infections (ALRI) in children under 5 years and that 265 000 of these resulted in death. However only $62 \%$ of children with ALRI are admitted to hospital with the vast majority of deaths happening in the community $(81 \%)^{5}$.

The introduction of molecular (PCR-based) diagnostics enable pathogens to be identified in many patients with community-acquired pneumonia, but it in many cases the initiating infection remains unidentified. Respiratory viruses are implicated in about $45 \%$ of pneumonia cases requiring hospitalization in children ${ }^{6}$ but some viruses (rhinovirus and adenovirus in particular) are found both in symptomatic and asymptomatic individuals ${ }^{7}$.

The relative importance of viral infections as a cause of pneumonia has increased not only because of improved diagnostics, but also because of the introduction of bacterial vaccines such as the Hib conjugate (HibCV) and pneumococcal conjugate vaccines (PCVs) ${ }^{8}$. Vaccination is also available for influenza and vaccination against varicella zoster, rubella and measles helps to prevent additional cases of viral pneumonia and its complications.

The burden of ALRI caused by viral pathogens indicates clearly that additional effective, durable and affordable vaccines are urgently needed.

\section{VIRAL VACCINES}

Current licensed vaccines include inactivated, subunit, vectored and live attenuated preparations. Inactivated vaccines may be made up of whole virus, split virus, subunit or virus-like particles. Whole virus is grown in culture and then inactivated using a variety of methods including chemical or heat treatments to render them non-pathogenic. Vaccines containing whole killed organisms are generally 
cheaper to produce but may have a disadvantageous safety (reactogenicity) or immunogenicity profile. Spilt virus vaccines are a type of inactivated vaccine, split using organic solvents or detergents. Subunit vaccines comprise isolated or biosynthetic viral proteins that are selected to stimulate appropriate protective immune response while avoiding adverse host reactions.

Some vaccines, especially those that are highly purified and refined, may need to the combined with adjuvants and/or require the inoculation of multiple doses to be immunogenic. Adjuvants augment the host's immune response to vaccination, normally by providing a collateral 'danger' signal via the innate immune system and thus boosting the protective acquired immune response. They enhance immunological memory, allowing greater optimised antigen presentation ${ }^{9}$. Examples of adjuvants include alum (aluminum salts), virosomes, MP59 and AS03.

\section{EXPERIMENTAL VACCINES}

There are many different innovative vaccine approaches that are currently in clinical development and for the most part these focus on directing pathogen genomic material to the target host immune cell. DNA vaccines involve the injection of DNA encoding specific antigens into muscle leading to de novo antigen expression and the stimulation of both B and T-cells. A major advantage of DNA vaccines is the stability, the absence of any infectious material and the possibility of rapid scale-up. Drawbacks include the difficulty of translating apparent benefits from animal models into man and the need for repeated and relatively large volume injections. Most ongoing trials are in the treatment of HIV and certain cancers, but there are some studies of DNA vaccines for influenza ${ }^{10,11}$.

Recombinant vector vaccines aim to introduce microbial DNA from an attenuated virus or bacteria using another pathogenic virus or bacteria to deliver genetic material to the appropriate host immune cell. Therefore, this closely mimics natural infection and triggers a corresponding immune response. Dendritic cell vaccines work in a similar way but exploit the immune systems' own antigen presenting cells to present pathogenic DNA. These are mostly being investigated in the context of HIV infection and cancer ${ }^{12}$. 


\section{CHALLENGE MODELS AND VACCINE DEVELOPMENT}

Animal models make for useful preliminary models for analyses of immune biology and identification of potential vaccine candidates. However animals and humans can differ in their immune responses and correlates of protection ${ }^{13}$, confounded by the fact that those who experience the most severe viral disease are not typically those studied in challenge models (infants, pregnant women and the elderly) ${ }^{14}$.

Below we will discuss some of the common causes of viral pneumonia, current vaccination programs, their efficacy and potential vaccine strategies for the future, including influenza, respiratory syncytial virus, parainfluenza and adenovirus.

\section{INFLUENZA}

Influenza virus is the commonest cause of viral pneumonia in adults and the only virus that has an established global vaccination program. Epidemics have been estimated to cause 2-5 million cases of severe illness and 250,000-500,000 deaths per year across the globe. Annual infection rates are estimated to be $5-10 \%$ in adults and $20-30 \%$ in children. Those at increased risk of severe disease are infants, the elderly, pregnant women and those with major co-morbidities ${ }^{15}$. Vaccination against influenza virus has been available since the 1940s and remains the most effective way of preventing disease.

There are 3 types of influenza: A, B and C ( $A$ and B causing most human disease). Influenza B is more genetically stable than influenza A, with less antigenic drift and consequent immunologic variation ${ }^{16}$. Influenza vaccines have to be re-formulated due to the constantly evolving nature of influenza viruses due to antigenic shift and drift in response to immunological pressure and reassortment events. Mutations in surface proteins hemagglutinin ( $\mathrm{HA})$ and neuraminidase (NA) accumulate under a variety of influences: an error-prone RNA polymerase, host immune pressures and co-infection of a host with multiple strains can lead to gene re-assortment.

Seasonal influenza vaccines vary depending on geographical region and are tailored to the circulating strains. Each year in February and September the World Health Organization (WHO) recommend 
viruses for inclusion in seasonal influenza vaccines in the southern and northern hemispheres, using information from classical re-assortment and reverse genetics techniques ${ }^{17}$.

In 2010, the United States Advisory Committee on Immunization Practices (ACIP) expanded the recommendation for influenza vaccination to include all individuals six months of age and older ${ }^{18}$. Globally however due to limited resources this is not always possible and therefore high-risk groups are prioritized (see Panel 1). Live attenuated vaccination is currently being introduced to protect children in the UK.

\section{Panel 1- Populations to prioritize for Influenza vaccination}

\section{Those at high risk for influenza-related complications:}

- 6 months through 4 years (59 months) of age

- $\quad \geq 50$ years of age

- Have chronic co-morbidities: pulmonary (e.g. COPD, asthma), cardiovascular (except hypertension), renal, hepatic, haematological (including sickle cell disease), metabolic (including diabetes mellitus), neurological (including neuromuscular/ neurodevelopmental) disorders

- Immunosuppressed (including immunosuppression caused by medications or by HIV)

- Pregnancy

- 6 months through 18 years of age and receiving long-term aspirin therapy (and therefore may be at risk for Reye syndrome after influenza virus infection).

- Morbid obesity (body mass index [BMI] $\geq 40$ for adults or $\mathrm{BMI}>2.33$ standard deviations above the mean for children)

\section{Environmental:}

- Nursing home residents and other long term care facilities

- Healthcare personnel

- Household contacts or caregivers of children $<5$ years and adults $\geq 50$ years of age

- Household contacts or caregivers of persons with medical conditions that put them at increased risk for severe complications of influenza

Adapted from following sources: Prevention and Control of Seasonal Influenza with Vaccines: Recommendations of the Advisory Committee on Immunization Practices - United States, 2013-2014. World Health Organization (WHO) Weekly epidemiological record vaccines against influenza WHO position paper, November 2012. 


\section{Types of Influenza Vaccines}

Licenced Influenza vaccines are inactivated (whole virus, split virus, or subunit) or live attenuated. Inactivated Influenza Vaccines (IIVs) are generally produced from highly purified, egg-grown influenza viruses and delivered intramuscularly or intradermally. A trivalent IIV has been available since 1978. In 2003 in the USA and in 2011 in Europe a live attenuated influenza vaccine (LAIV) for intranasal use was approved for use in healthy adults and children.

\section{Trivalent or Quadrivalent?}

Trivalent vaccines contain antigens from two A strains and one B strain from a single lineage. Historically, there are several examples of mismatch between the vaccine and the circulating B strain have occurred. In the years 2001 through to 2011, the predominant circulating influenza B lineage was different from that contained in the trivalent vaccine in five out of ten seasons ${ }^{19}$. It is now generally recommended that quadrivalent influenza vaccines should be used that contain two influenza $A$ strains (H1N1 and H3N2 subtypes) and two influenza B strains (Victoria and Yamagata lineages).

\section{Vaccine Efficacy}

The effectiveness of influenza vaccines is related to the age and immune competence of the recipient, as well as the antigenic matching of vaccine to circulating strains. A recent Cochrane review of inactivated seasonal flu vaccination in healthy adults showed an overall efficacy in preventing confirmed influenza of $60 \%$ (a number needed to vaccinate (NNV) of 719$)^{20}$. In this review, it was concluded that vaccination did not have a demonstrable effect on hospital admissions or working days lost ${ }^{20}$. In years with poor vaccine matching, benefit is much lower, although the vaccine can still provide protection against more severe outcomes ${ }^{21}$. A case-control study showed previous vaccinees achieved mortality reduction rates of up to $75 \%$ (95\% Cl 31 to $91 \%)$, but only a $9 \%$ (95\% Cl 0 to $59 \%$ ) reduction in mortality was seen in those that had never received a vaccination ${ }^{22}$.

Efficacy for the LAIV in healthy adults is similar to that of inactivated vaccine ${ }^{20}$, but depends on the 'take' of the vaccine on the mucosal surface. LAIV given intra-nasally as a large particle spray appears 
superior to inactivated trivalent influenza vaccine with respect to protection against influenza strains that diverge from the vaccine strain ${ }^{23}$, indicating a degree of heterosubtypic protection.

\section{INFLUENZA VACCINATION IN AT RISK POPULATIONS}

For a list of vaccination recommendations for at risk populations, see $\underline{\text { Panel }}^{24-26}$.

\section{Pregnant Women}

It is recommended that if vaccination is in short supply, the first population group targeted should be pregnant mothers ${ }^{25}$. This is because influenza may be more severe in pregnancy, and that it increases perinatal infant mortality, prematurity, smaller birth size and weight ${ }^{27}$. Maternal vaccination may also benefit the newborn child ${ }^{28}$.

The use of the IIV is recommended in pregnancy. It has been shown that vaccination reduces risk to both mother and infant (via passive immunity). An Indian study of 340 women demonstrated a $63 \%$ reduction of proven influenza illness in infants up to 6 months of age and prevention of approximately a third of febrile respiratory illnesses in mothers and young infants ${ }^{29}$. In addition, maternal immunization results in the presence of antibody titers against Influenza-A vaccine subtypes in a significant proportion of mothers and their infants. Hemagglutination-inhibition antibodies for influenza A subtypes are greater in infants of vaccinated mothers up to 20 weeks of age however the immunogenicity varies dependent on $\operatorname{strain}^{30,31}$.

\section{Children}

LAIV is now the vaccine of choice for healthy children aged 2-18 years, due to the significant weight of evidence suggesting vaccine effectiveness ${ }^{32}$. A meta-analysis of nine randomized controlled trials compared LAIV to placebo demonstrated a relative efficacy of $77 \%$ against antigenically similar strains and $72 \%$ efficacy regardless of antigenic similarity, whilst comparison with TIV showed that $46 \%$ fewer children experienced influenza illness ${ }^{33}$. Other studies have also showed LAIV to consistently provide a higher level of protection in children when compared to inactivated vaccines or placebo ${ }^{34-36}$. Regarding 
other vaccine types, a Cochrane review in children aged 6 months to 2 years of age showed inactivated trivalent influenza vaccine is not significantly more efficacious than placebo ${ }^{34}$. However a 2011 randomised controlled trial involving 4707 children aged 6 to 72 months (1941 vaccinated) showed that the adjuvant influenza vaccine (MF59 adjuvant trivalent vaccine) was significantly more effective than control or lone trivalent vaccine at preventing influenza like illness ${ }^{37}$ Interestingly when given to children (age 6-15 years) the TIV vaccine has been associated with an increase in the rates of noninfluenza respiratory virus infection ${ }^{38}$. This study was carried out in the pandemic season 2008-2009, however this data has not been replicated in different age groups (under 5 years and greater than 50 years) $)^{39}$

\section{Older Adults}

The majority of deaths associated with influenza occur in frail elderly persons ${ }^{18,40}$ therefore influenza vaccination is generally recommended for all those over the age of 65 years ${ }^{18}$. This is particularly important for those suffering from co-morbidities, such as chronic lung disease, heart failure or diabetes. Effectiveness of vaccination at preventing influenza in the elderly is of ongoing debate, with a great degree of heterogeneity in published studies ${ }^{41}$. A robust randomized control trial in this age group showing significant benefit of vaccine in older adults is lacking ${ }^{42}$.

Comprehensive reviews come to differing conclusions dependent on study design, methodology, inclusion criteria and varying approaches to the correction of season-to-season variation of vaccine matching ${ }^{35,43,44}$. Two large meta-analyses assessing the same body of evidence have come to differing conclusions, whilst one group concluded that there was insufficient evidence with respect to older adults ${ }^{42}$, the other concluded when virus was circulating, vaccination reduced influenza-related and non-fatal complications by $28 \%$ and confirmed cases of influenza by $5 \%{ }^{45}$. These differences highlight the importance of taking into account the large number of factors that affect the estimation of influenza vaccine effectiveness and the importance of careful and thorough evaluation. Failure to find an effect may be as much due to methodological shortcomings as to lack of efficacy. 
To improve vaccine immunogenicity in older age groups, higher dose vaccines have been trialed, resulting in significantly greater antibody responses ${ }^{46}$. Promising data has also been seen with the use of adjuvanted vaccines ${ }^{47}$. LAIV is mostly ineffective in older adults due to previous immunity hindering local mucosal infection and therefore vaccine induced immune response ${ }^{48}$.

\section{Asthmatics}

Globally, asthma is considered a priority group for vaccination ${ }^{24,49}$, and clear guidelines can result in greatly increased uptake in vaccination ${ }^{32}$. However, there are inconsistent reports of vaccine effectiveness in persons with asthma largely due to differences in patient subgroups, research methodology and variability in the definition of asthma.

LAIV has been demonstrated to cause a $35 \%$ relative risk reduction in culture-confirmed influenza when compared to TIV in a large trial $(n=2229)$ of asthmatic children aged 6-17 with no increase in exacerbations of their underlying asthma ${ }^{50}$. A study of younger children aged 6-59 months concluded that LAIV reduced proven influenza cases by $55 \%$ when compared to TIV but the youngest children (aged between 6-11 months) experienced a higher hospitalized rate after LAIV compared to TIV (6.1\% vs $2.6 \%)^{36}$. Because of the small but significant potential for LAIV to cause wheeze and increased hospital admissions, the Centres for Disease Control $(C D C)$ recommend avoiding its use in children aged 2-4 years who have had an episode of wheeze in the preceding 12 months ${ }^{24}$.

A Cochrane systematic review concluded that vaccination with inactivated influenza vaccination did not result in a significant reduction in the number, duration or severity of influenza-related asthma exacerbations but did improve symptoms and also noted that there was no evidence that LAIV vaccine itself is actually causative of asthma exacerbations ${ }^{51}$.

Reports of low effectiveness can adversely affect uptake of vaccination amongst patients whilst a healthcare worker recommendation to vaccinate is highly predictive of adherence ${ }^{52}$. 


\section{Pandemic Influenza Vaccines}

Rapid deployment of vaccines as part of the response to pandemic threats is often problematic, largely due to the delay in production of new vaccines and the speed of spread of novel influenza strains. Three influenza pandemics occurred last century: 1918, 1957 and 1968 with a total mortality of 50-100 million people $^{53}$. In 2009 an Influenza pandemic was declared by the WHO (caused by the influenza A H1N1 virus). The emergence of a new influenza strain genetically very different caused a pandemic with significant mortality even in persons with no co-morbidities ${ }^{54}$. This is due to lack of herd immunity and vaccinations not being matched to the novel influenza strain.

Seasonal vaccines generally offer little or no protection against novel pandemic strains; although there are hints that weak heterosubtypic protection may occur with LAIV. Developing a novel influenza vaccine requires safety and immunogenicity testing, but generally not field trials of efficacy. Even with expedited testing, production inevitably lags behind the timeline required for novel pandemic strains. A new vaccine typically takes 4-6 months to make, by which time the pandemic peak may be passed. Second, antigens from some novel influenza strains (e.g. avian H5N1) are poorly immunogenic, making effective induction of immunity with vaccination difficult even with the use of adjuvants and multiple doses $^{55}$. Ideally, a universal influenza vaccine that provides broadly cross-reactive protection through the induction of antibodies and/ or T cells to the conserved regions of the virus need to be developed to counter future epidemic and pandemic threats ${ }^{53}$.

\section{Correlates of Protection - Influenza Vaccination}

Influenza vaccination induces antibodies, primarily against the major surface glycoproteins HA and NA. Antibodies directed against HA are the most widely accepted correlate of protection ${ }^{56}$. HA is the viral receptor-binding protein and antibodies that are directed to epitopes located in or near to this can prevent binding of the virus to its receptor and thus its infectivity. Titres of 1:40 HA inhibition antibody or greater have been shown to provide $50 \%$ level of protection in healthy adults and this concentration of vaccine induced antibody is used as a benchmark during vaccine development ${ }^{57}$. This is not necessarily the case for LAIV, where secretory immunoglobulin A is a better correlate of mucosal protection $^{58}$ 
T cells are abundant in the lung mucosa and have the ability to recognise conserved internal viral proteins. Although not preventing infection higher peripheral CD4+ T cell are associated with lower virus shedding and less severe influenza illness, even in the absence of specific antibodies ${ }^{59}$. Presence of cross-reactive CD8+ $T$ cells have also been associated with a reduced symptom burden as well as higher levels of interferon- $\gamma$ (IFN- $\gamma$ ) and interleukin-2 (IL-2) in influenza infection ${ }^{60}$. As T lymphocytes (CD4+ or $\mathrm{CD8}+$ ) preferentially recognize the more conserved internal proteins, this creates great potential for broad responses ${ }^{61}$.

As already mentioned, frail elderly persons do not mount as good an immune response as younger people. T cell senescence is well described, particularly in studies of cytotoxic T cells. In a study of noninstitutionalized elderly persons, pre-vaccination interferon- $\gamma$ was ten-times lower, IL-10 three-times greater and the Th1:Th2 ratio was lower in those that developed influenza in the weeks following vaccination ${ }^{62}$.

\section{The Future of Influenza Vaccines}

Given the increasing emergence of influenza strains that are resistant to varying antiviral therapies: (adamantaines ${ }^{63}$, rimantadine, zanamivir and oseltamivir ${ }^{64}$ ) and the fact that classical influenza vaccines must be updated regularly to match the new strains, prevention of disease using novel vaccine platforms should be given some urgent priority.

Cell culture technology offers the potential to produce large quantities of vaccine antigen, and adjuvants allowing for less viral antigen to be used. MF59 and AS03 have both been shown to be safe and effect and are now licenced adjuvant vaccines ${ }^{65}$. Recently two synthetic Toll-like receptor (TLR) adjuvants (IZ105 and IV270) have shown promise in murine challenge studies ${ }^{66}$.

The most promising universal influenza vaccines are those that induce cross-reactive humoral and cell mediated responses. Universally conserved antigens with some promise include the extracellular 
domain of $\mathrm{M} 2{ }^{67}$, but this locus is poorly immunogenic ${ }^{68}$. The stalk portion of HA (HA2) is an attractive target as it contains several conserved epitopes that are highly conserved ${ }^{69}$.

The non-structural NS1 protein deletion blocks viral replication and stimulates an antibody and cellular immune response. Intranasal delivery of a live NS1 vaccine has been shown to be safe and immunogenic ${ }^{70}$. Vaccines that induce $C D 8 T$ cell responses targeting viral nucleoprotein (NP), matrix protein 1 (M1) and polymerase basic 1 (PB1) offer the prospect of universal influenza vaccines that might additionally accelerate viral clearance ${ }^{71}$ (Panel 2).

\section{Panel 2: Current Issues in Influenza Vaccinology}

Improving Traditional Approaches

How can durability of protection be enhanced?

How might adjuvants be best used?

How can vaccines be targeted to appropriate risk groups?

Better influenza strain prediction

\section{Future Vaccine Development}

How to develop universal vaccines against all existing and emerging strains

Evaluation of cross reactive stalk/stem antibodies

Overcoming weak immunogenicity of some influenza antigens

Optimization of vaccine delivery methods

\section{Improving Manufacturing}

Acceleration of production techniques

Manufacture of new vaccines to meet emerging/zoonotic strains

Improved stability and convenient formulation 


\section{RESPIRATORY SYNCYTIAL VIRUS}

\section{Burden of Disease and Early Attempts at Vaccination}

As recently reviewed ${ }^{72}$ respiratory syncytial virus (RSV) is responsible for more than 30 million episodes of acute respiratory tract infection (ARI) globally. With up to $20 \%$ of infants under the age of 1 requiring medical attention because of RSV disease, the need for an effective vaccination that can elicit durable protection in at-risk groups is clear ${ }^{73,74}$.

Indeed, it is surprising that whilst other common respiratory pathogens such as influenza virus and $H$. influenza have established immunization programs, a vaccine against RSV remains elusive. This is in part due to studies of in the 1960s, which showed that alum-precipitated formalin-inactivated RSV vaccine (FI-RSV) can augment subsequent disease ${ }^{75,76}$. Such vaccines not only fail to prevent infection, but dramatically increase hospitalization rates in young children during natural infection. This appears to be associated with an induction of poorly-neutralizing antibody, skewing towards the production of Th2 cytokines ${ }^{77,78}$ and a local deficit in regulatory $T$ cells ${ }^{79}$. These events hampered efforts in vaccine discovery, but in recent years academics, vaccine manufacturers and international organizations such as WHO have made development of safe and effective vaccines a realistic prospect ${ }^{80}$.

\section{Antigenic Targets for Prophylaxis and Vaccination}

RSV is a negative-sense, single stranded RNA virus consisting of 10 genes that encode 11 proteins; the surface glycoproteins $\mathrm{F}$ and $\mathrm{G}$ are responsible for fusion and attachment to the host cell membrane respectively. $\mathrm{F}$ and $\mathrm{G}$ are both targets for neutralizing antibody and are the key vaccine antigens ${ }^{81}$.

F protein is crucial in facilitating the fusion of the virus and cell membrane, thereby permitting cellular infection (and incidentally, of cell fusion into syncytia). Prior to fusion, (pre-F) protein has a metastable conformation and forms trimeric structures extending $11 \mathrm{~nm}$ from the surface. Upon fusion with the host cell membrane the structure extends to $16 \mathrm{~nm}$ and assumes a new post-fusion conformation that is highly stable. Both pre-F and post-F forms can be found on the viral surface and share two major sites for antibody binding; however, neutralizing antibody is predominantly against the less stable pre-fusion form of $F$, which is now the generally preferred component of RSV vaccine candidates ${ }^{82}$. 
The $\mathrm{G}$ protein can be either membrane bound or secretory. The soluble form may act as a decoy to assist in viral evasion ${ }^{83}$, but $\mathrm{G}$ (in either form) also engages the CX3CR1 fractalkine (CX3CL1) receptor, demonstrated to impair interferon (IFN) production by epithelial and dendritic cells in vitro ${ }^{84}$. The CX3C motif is located within the central conserved domain of $\mathrm{G}$, flanked by mucin-like serine-threonine rich domains that are heavily $O$-glycosylated.

Vaccination with layer-by-layer nanoparticles (LbL-NP) carrying the G protein CX3C motif has recently been shown to induce blocking antibodies and attenuate RSV pathogenesis in mice ${ }^{85}$. However, given the degree of glycosylation and variability of $\mathrm{G}$ protein coupled with recent advancements in structural biology techniques, $\mathrm{F}$ protein has been identified as being the most promising target for vaccination ${ }^{86}$.

Although antibody induction is the major goal of vaccination against RSV disease, the recent demonstration that local mucosal CD8 T cells play a part in controlling viral load offers the prospect that T cell induction by vaccines might also be beneficial ${ }^{87-89}$.

\section{RSV Prophylaxis}

Palivizumab is a humanized monoclonal antibody against F protein. It targets antigenic site II on the viral protein and works prophylactically (but not therapeutically) to reduce hospitalization rates due to RSV bronchiolitis in infants ${ }^{82}$. It is licensed for use in selected high-risk infants less than 1 year of age, and is given as five monthly does by intramuscular injection. In some cases, it can be given in the second year of life ${ }^{90}$, but finds little use outside these indications. Disadvantages include prohibitive cost and the lack of efficacy in those with established disease. Most failures of prophylaxis reflect delay in onset of prophylaxis or in the administration or scheduling of monthly injections. The seasonality is variable depending on geographical location ${ }^{72,91}$.

Recent evidence suggests that palivizumab also reduces the prevalence of wheeze in the first year of life, presumably by delaying RSV infection beyond the critical first few months of life. This effect occurs 
after the end of treatment, lending strength to the argument that wheeze is a delayed effect of bronchiolitis in premature infants ${ }^{83}$.

Another monoclonal antibody, motavizumab, was developed with greater affinity to site II; this showed an $87 \%$ relative reduction (relative risk $[R R] 0 \cdot 13,95 \% \mathrm{Cl} 0 \cdot 08-0 \cdot 21$ ) in the proportion of healthy-term infants admitted to hospital with RSV when compared to placebo but has subsequently been discontinued due to non-superiority to palivizumab and side effects related to skin reactions. In native American (Navajo) infants born at 36 weeks' gestational age, motavizumab is surprisingly ineffective at preventing post-RSV wheeze ${ }^{92}$.

\section{RSV Vaccine Development}

Due to the requirement of vaccines for diverse target populations (young infants, older infants, pregnant women and the elderly), multiple strategies may be required. These include live attenuated, particle-based, subunit and vector-based vaccine approaches. Young RSV-naive infants, for example, might benefit from live-attenuated vaccines while adults (who have experienced multiple infections) or immunosenescent older individuals may require different approaches.

An RSV F nanoparticle vaccine (Novavax Inc., 9920 Belward Campus Drive, Rockville, MD 20850, USA) is currently the most advanced vaccine in clinical trials for the protection of older adults (60 years of age and older), having been shown to be well-tolerated and immunogenic in healthy adults. However, a phase 3 clinical trial in 11,856 older adults failed to meet its primary objective of preventing RSVassociated lower respiratory tract disease or its secondary objective of reducing all symptomatic respiratory disease due to RSV [NCT02608502]. The reasons for this failure of efficacy are yet to be established but a milder RSV season was noted during the study and the vaccine was tolerated safely. A related study in women in their third trimester of pregnancy is being carried out with the aim of reducing RSV lower respiratory infection in their infants up to 3 months of age [NCT02624947].

A promising live attenuated vaccine, MEDI-559 (MedImmune/National Institute of Allergy and Infectious Diseases, Bethesda, MD, USA) induces a substantial immune response in $59 \%$ of children 
aged 5 to 24 months of age $\mathrm{e}^{93}$. A range of other candidate vaccines are moving forwards from the preclinical testing stage to clinical trials, including a mucosal vaccine based on bacteria-like particles coated in F (Mucosis BV, NL). The RSV vaccines in different phases of development are shown in Table $\mathbf{1}$.

Table 1- Snapshot of Current RSV Vaccines

\begin{tabular}{|c|c|c|c|c|c|}
\hline & Preclinical & Phase I & Phase II & Phase III & $\begin{array}{l}\text { Market } \\
\text { approved }\end{array}$ \\
\hline $\begin{array}{l}\text { Live } \\
\text { attenuated }\end{array}$ & 7 & 5 & 0 & 0 & 0 \\
\hline Inactivated & 1 & 0 & 0 & 0 & 0 \\
\hline Particle & 12 & 1 & 1 & 2 & 0 \\
\hline Subunit & 10 & 2 & 2 & 0 & 0 \\
\hline RNA/DNA & 4 & 0 & 0 & 0 & 0 \\
\hline Vector & 8 & 3 & 0 & 0 & 0 \\
\hline $\begin{array}{l}\text { Other (incl. } \\
\text { antibody) }\end{array}$ & 2 & 1 & 0 & 0 & 1 \\
\hline Total $n=62$ & 44 & 12 & 3 & 2 & 1 \\
\hline
\end{tabular}

From PATH. Vaccine development - Vaccine Development Global Program. Available at: http://sites.path.org/vaccinedevelopment/respiratory-syncytial-virus-rsv/vaccine-development/. Accessed May 19, 2016.

\section{Overcoming Hurdles for RSV Vaccine Development}

The ideal RSV vaccine would elicit long-lasting upper and lower respiratory tract protection, be well tolerated in infants and adults alike and be free of risk of subsequent disease augmentation. Natural infection causes only partial protection against re-infection despite the low rates of antigenic variability, which indicates that an effective vaccine needs to surpass natural infection but avoid causing excessive T-cell mediated host immune disease. This is especially important in infants with an immature immune system ${ }^{94}$. These young infants are especially at risk of severe RSV infection, and may benefit from maternal immunization ${ }^{95}$. This aims to induce protective antibody that is transferred to the child via the 
placenta and breast milk, but accurate correlates of protection as well as an understanding of the optimal route and timing of maternal vaccination is lacking. Vaccine effectiveness is typically assessed by the level of induced systemic RSV-specific neutralizing antibodies but this may not be an accurate predictor of durable immunity, with a human challenge model of RSV infection suggesting that the presence of mucosal RSV-specific IgA may provide a better correlate of protection ${ }^{96}$. A non-profit organization, PATH, is developing an international RSV antibody reference standard to permit greater comparability between research studies ${ }^{97}$. These wide-ranging and intensive efforts to develop a range of suitable vaccines, raises the hope of successfully combating RSV-mediated disease in the not too distant future.

\section{PARAINFLUENZA VACCINATION}

Parainfluenza viruses (PIV) are single-stranded RNA viruses that, like RSV, are members of the Paramyxoviridae family and cause an approximately similar spectrum of symptoms. There are four major serotypes of PIV (1-4) with PIV1 and PIV2 being associated with croup, PIV3 with pneumonia and PIV4 with upper respiratory tract infection ${ }^{98}$.

The usual course of infection results in a mild self-limiting illness but susceptible individuals, particularly those who are immunocompromised, can experience a more serious, protracted illness marked by severe pneumonia and prolonged viral shedding ${ }^{99,100}$. Most children by the age of 5 years and virtually all adults have antibodies to PIV with multiple reinfections common but usually characterized by only mild disease limited to the nose and pharynx ${ }^{101,102}$. As PIV3 is the most common serotype, which has the ability to cause bronchiolitis in infants, most vaccine efforts have been directed towards it.

The virus contains six proteins that are common across serotypes. Two of them (fusion glycoprotein $\mathrm{F}$ and hemagglutinin-neuraminidase glycoprotein $\mathrm{HN}$ ) are present on the viral surface and are the main targets for neutralizing antibodies. There is as yet no vaccine to prevent PIV infection despite nearly 60 years of research and development. Current strategies include the use of nasally delivered liveattenuated vaccines, the use of reverse genetics, bovine/human chimeras and subunit vaccines that express $\mathrm{F}$ and $\mathrm{HN}$ proteins ${ }^{103}$. 
The live-attenuated vaccine HPIVcp45 is derived from a live strain of HPIV3 that has undergone coldpassage $(c p) 45$ times. The accumulation of 15 attenuating mutations has rendered it non-pathogenic, and it is undergoing phase 1 trials in both adults and infants. It is reported to have a $94 \%$ infectivity rate and lacks transmissibility ${ }^{104-106}$. A larger phase II study with a population size of 380 children aged 6-18 months, consisting of 226 seronegative children demonstrated that it generated adequate antibody response in $84 \%$ of seronegative recipients with no significant difference in adverse events when compared to placebo ${ }^{107}$.

In other trials, a recombinant form of the vaccine (rHPIV3cp45), re-derived from cDNA, shows a shorter passage time and reduced the risk of contamination or reversion ${ }^{108}$. It has been used in a phase 1 study of 40 seronegative children between 6-35 months and generates virus-specific antibodies with a tolerable safety profile ${ }^{109}$. Another trial utilizing rHPIV3cp45 in healthy young seronegative infants between 6-12 months demonstrated strong immunogenicity. These studies involved the delivery of multiple doses of vaccine with appropriate intervals which is necessary to sustain durable immune responses and children in particular are likely to benefit from the nasal route of administration due to the ability to generate protective mucosal and systemic immunity ${ }^{108}$.

An antigenically similar bovine PIV3 (BPIV3) vaccine has been developed either alone or as a chimeric recombinant virus with human PIV3 (rB/HPIV3). The latter was highly restricted in replication in adults and seropositive children but caused significant infectivity amongst seronegative children ${ }^{110-112}$.

HPIV1 and HPIV2 vaccines are in development but are at a less advanced stage with only three trials that have undergone human clinical trial testing at present [ClinicalTrials.gov identifiers: NCT00641017, NCT00186927, NCT01139437]. Results from a recent live-attenuated HPIV1 vaccine trial suggested that it is appropriately restricted in adults and seropositive children but inadequately infectious in seronegative children highlighting the challenges faced in developing novel vaccines that are safely tolerated but also have the ability to cause sufficient immunogenicity in their target populations ${ }^{113}$. 
Delivery of combined vaccines to young infants that target PIV and RSV to elicit broad protective immunity may also be a feasible prospect in this age group and if successful could reduce the significant burden of disease due to these common respiratory pathogens ${ }^{114,115}$.

\section{ADENOVIRUS}

Adenoviruses were first discovered in $1953^{116}$. They display diverse respiratory manifestations from simple upper respiratory tract infections to severe fatal pneumonia ${ }^{117}$. Those most at risk are children under 5 years old, the immunocompromised (most notably those who have received bone marrow transplants ${ }^{118}$ and those living in crowded conditions such as the military. The majority of acute respiratory infection among U.S. military trainees is attributable to adenovirus ${ }^{119}$.

The introduction of an adenovirus vaccine has greatly reduced military respiratory infection morbidity since its introduction in the 1970s. However in 1995 the sole manufacturer ceased production of this vaccine. Over a 2 year period in the nineties when adenovirus vaccines were diminishing 3413 throat cultures were taken from trainees with acute respiratory illnesses with 1814 (53.1\%) being positive for adenovirus. Those who were unvaccinated $(n=2322)$ were more likely to yield a positive adenovirus culture (OR, 13.2) especially for serotypes 4 or 7 (OR, 28.1). During this period there were also a number of epidemics of adenovirus in these military bases affecting thousands of trainees ${ }^{120}$.

In 2011 a live vaccine against adenovirus type 4 and 7 (oral) was licensed in the US and rolled out within the military in that year. The phase 3 trial revealed a vaccine efficacy rate of $99.3 \%$ (with only one episode of febrile respiratory illness in the vaccinated group) $73 \%$ of vaccine recipients seroconverted to ADV-4 while $63 \%$ seroconverted to ADV-7 by Day $28^{121}$. After re-introduction of the vaccine episodes of febrile respiratory illness reduced dramatically ${ }^{122}$.

\section{THE FUTURE OF VIRAL VACCINATION}

Vaccination is one of the most successful disease prevention strategies of the last century. However, we sadly lack vaccines against some important respiratory viruses; with the exception of influenza and adenovirus, there are no licensed vaccines against common causes of viral pneumonia. One of the 
major issues it to better understand the ways in which viruses evade immune protection, and how this information can be used to induce long lasting, robust and non-pathogenic immunity at the mucosal surface. It is possible that vaccines might be designed that would prevent symptomatic disease, while allowing infection (and possibly onward transmission) to occur. Such a vaccine would have the disadvantage of having a lesser impact on community circulation, thereby protecting the vaccine recipient but not others at risk. It is to be hoped that a new generation of vaccines will be developed that induce a balanced protective cell mediated and antibody response and confer durable crossprotection against novel viral strains. With advances in virology, immunology and vaccinology, it is to be hoped that this new dawn will soon be upon us (Panel 3).

\section{Panel 3: Current Research Gaps}

\section{Questions}

How can optimal mucosal immunity be induced?

Does T cell immunity reduce severity or enhance recovery?

How can universal vaccination be best achieved?

\section{Risks}

Might novel vaccines enhance disease?

Will viral resistance emerge?

What are the drawbacks of adjuvants? 


\section{REFERENCES}

1. Rudan I, O'Brien KL, Nair H, et al. Epidemiology and etiology of childhood pneumonia in 2010: estimates of incidence, severe morbidity, mortality, underlying risk factors and causative pathogens for 192 countries. J Glob Health. 2013;3(1):10401. doi:10.7189/jogh.03.010401.

2. Joos L, Chhajed PN, Wallner J, et al. Pulmonary infections diagnosed by BAL: A 12-year experience in 1066 immunocompromised patients. Respir Med. 2007;101(1):93-97. doi:10.1016/j.rmed.2006.04.006.

3. Falsey AR, Walsh EE. Viral pneumonia in older adults. Clin Infect Dis. 2006;42(4):518-524.

4. Naghavi $\mathrm{M}$, Wang $\mathrm{H}$, Lozano $\mathrm{R}$, et al. Global, regional, and national age-sex specific all-cause and cause-specific mortality for 240 causes of death, 1990-2013: a systematic analysis for the Global Burden of Disease Study 2013. Lancet. 2015;385(9963):117-171. doi:10.1016/S01406736(14)61682-2.

5. Nair H, Simoes EAF, Rudan I, et al. Global and regional burden of hospital admissions for severe acute lower respiratory infections in young children in 2010: A systematic analysis. Lancet. 2013;381(9875):1380-1390. doi:10.1016/S0140-6736(12)61901-1.

6. Michelow IC, Olsen K, Lozano J, et al. Epidemiology and clinical characteristics of communityacquired pneumonia in hospitalized children. Pediatrics. 2004;113(4):701-707. doi:10.1542/peds.113.4.701.

7. Homaira N, Luby S, Hossain K, et al. Respiratory Viruses Associated Hospitalization among Children Aged <5 Years in Bangladesh: 2010-2014. PLoS One. 2016;11(2):e0147982.

8. Moberley S, Holden J, Tatham DP, Andrews RM. Vaccines for preventing pneumococcal infection in adults. Cochrane database Syst Rev. 2013;1(1):CD000422. doi:10.1002/14651858.CD000422.pub3.

9. Jalilian B, Christiansen SH, Einarsson HB, Pirozyan MR, Petersen E, Vorup-Jensen T. Properties and prospects of adjuvants in influenza vaccination - messy precipitates or blessed opportunities? Mol Cell Ther. 2013;1(1):2. doi:10.1186/2052-8426-1-2.

10. Zhang $\mathrm{H}$, El Zowalaty ME. DNA-based influenza vaccines as immunoprophylactic agents toward universality. Future Microbiol. 2015;11(1):153-164. doi:10.2217/fmb.15.110. 
11. Bicho D, Queiroz JA, Tomaz CT. Influenza Plasmid DNA Vaccines: Progress and Prospects. Curr Gene Ther. 2015;15(6):541-549.

12. Palucka K, Banchereau J. Dendritic-Cell-Based Therapeutic Cancer Vaccines. Immunity. 2013;39(1):38-48. doi:10.1016/j.immuni.2013.07.004.

13. Shultz LD, Brehm MA, Garcia-Martinez JV, Greiner DL. Humanized mice for immune system investigation: progress, promise and challenges. Nat Rev Immunol. 2012;12(11):786-798. doi:10.1038/nri3311.

14. Pollard A, Savulescu J, Oxford J, et al. Human microbial challenge: the ultimate animal model. Lancet Infect Dis. 2012;12(12):903-905. doi:10.1016/S1473-3099(12)70292-X.

15. WHO. WHO Seasonal Influenza. Bulletin of the World Health Organization. http://www.who.int/mediacentre/factsheets/fs211/en/. Published 2013. Accessed May 24, 2016.

16. Centers for Disease Control and Prevention. Epidemiology and Prevention of VaccinePreventable Diseases. CDC Pink Book. http://www.cdc.gov/vaccines/pubs/pinkbook/flu.html. Published 2015. Accessed May 24, 2016.

17. WHO. Recommended composition of influenza virus vaccines for use in the 2016-2017 northern hemisphere influenza season. http://www.who.int/influenza/vaccines/virus/recommendations/201602_recommendation.p df?ua=1. Published 2016. Accessed May 24, 2016.

18. Centers for Disease Control and Prevention. Prevention and control of influenza with vaccines: recommendations of the Advisory Committee on Immunization Practices (ACIP), 2010. Morbidity and mortality weekly report.

http://www.cdc.gov/mmwr/preview/mmwrhtml/rr5908a1.htm. Published 2010. Accessed May 24, 2016.

19. Ambrose CS, Levin MJ. The rationale for quadrivalent influenza vaccines. Hum Vaccines Immunother. 2012;8(1):81-88. doi:10.4161/hv.8.1.17623.

20. Demicheli V, Jefferson T, La A, Ferroni E, Rivetti A, C DP. Vaccines for preventing influenza in healthy adults ( Review ). Cochrane Database Syst Rev. 2014;(3).

21. Tessmer A, Welte T, Schmidt-Ott R, et al. Influenza vaccination is associated with reduced 
severity of community-acquired pneumonia. Eur Respir J. 2011;38(1):147-153.

doi:10.1183/09031936.00133510.

22. Ahmed AH, Nicholson KG, Nguyen-Van-Tam JS. Reduction in mortality associated with influenza vaccine during 1989-90 epidemic. Lancet. 1995;346(8975):591-595. doi:10.1016/S0140-6736(95)91434-X.

23. Belshe R, Lee M-S, Walker RE, Stoddard J, Mendelman PM. Safety, immunogenicity and efficacy of intranasal, live attenuated influenza vaccine. Expert Rev Vaccines. 2004;3(6):643654. doi:10.1586/14760584.3.6.643.

24. Centre for Disease Control and Prevention, Report MW. Prevention and control of seasonal influenza with vaccines. Recommendations of the Advisory Committee on Immunization Practices--United States, 2013-2014. MMWR, Morb Mortal Wkly Rep. 2013;62(RR-07):1-43. http://www.ncbi.nlm.nih.gov/pubmed/24048214.

25. WHO. Vaccines against influenza WHO position paper - November 2012. Weekly epidemiological record. http://www.who.int/wer/2012/wer8747.pdf?ua=1. Published 2012. Accessed May 24, 2016.

26. The Department of Health, Public Health England. The Department Health/ Pubic Health England: The national flu immunisation programme 2015/16. https://www.gov.uk/government/uploads/system/uploads/attachment_data/file/526144/An nual_flu_letter_24_03_15superseded.pdf. Published 2015. Accessed May 27, 2016.

27. Pierce $M$, Kurinczuk JJ, Spark $P$, Brocklehurst $P$, Knight $M$. Perinatal outcomes after maternal 2009/H1N1 infection: national cohort study. BMJ. 2011;342:d3214. doi:10.1136/bmj.d3214.

28. Phadke VK, Omer SB. Maternal vaccination for the prevention of influenza: current status and hopes for the future. Expert Rev Vaccines. 2016:1-26 [Epub ahead of print]. doi:10.1080/14760584.2016.1175304.

29. Zaman K, Roy E, Arifeen SE, et al. Effectiveness of maternal influenza immunization in mothers and infants. N Engl J Med. 2008;359(15):1555-1564. doi:10.1542/gr.21-1-1.

30. Steinhoff MC, MacDonald N, Pfeifer D, Muglia LJ. Influenza vaccine in pregnancy: policy and research strategies. Lancet. 2014;383(9929):1611-1613. doi:10.1016/S0140-6736(14)60583-3.

31. Steinhoff MC, Omer SB, Roy E, et al. Influenza immunization in pregnancy--antibody 
responses in mothers and infants. N Engl J Med. 2010;362(17):1644-1646.

doi:10.1056/NEJMc0912599.

32. Centre for Disease Control and prevention. Vaccination coverage among persons with asthma -- United States, 2010-2011 influenza season. Morbidity and mortality weekly report. http://www.cdc.gov/mmwr/preview/mmwrhtml/mm6248a1.htm. Published 2013. Accessed May 24, 2016.

33. Rhorer J, Ambrose CS, Dickinson S, et al. Efficacy of live attenuated influenza vaccine in children: A meta-analysis of nine randomized clinical trials. Vaccine. 2009;27(7):1101-1110. doi:10.1016/j.vaccine.2008.11.093.

34. Jefferson T, Rivetti A, Harnden A, Di Pietrantonj C, Demicheli V. Vaccines for preventing influenza in healthy children. Cochrane Rev. 2012;(2). doi:10.1002/14651858.CD004879.pub4.

35. Osterholm MT, Kelley NS, Sommer A, Belongia EA. Efficacy and effectiveness of influenza vaccines: A systematic review and meta-analysis. Lancet Infect Dis. 2012;12(1):36-44. doi:10.1016/S1473-3099(11)70295-X.

36. Belshe RB, Edwards KM, Vesikari T, et al. Live attenuated versus inactivated influenza vaccine in infants and young children. N Engl J Med. 2007;356(7):685-696. doi:10.1056/NEJMoa065368.

37. Vesikari T, Knuf $M$, Wutzler $P$, et al. Oil-in-water emulsion adjuvant with influenza vaccine in young children. N Eng/J Med. 2011;365(15):1406-1416. doi:10.1056/NEJMoa1010331.

38. Cowling BJ, Fang VJ, Nishiura $\mathrm{H}$, et al. Increased risk of noninfluenza respiratory virus infections associated with receipt of inactivated influenza vaccine. Clin Infect Dis. 2012;54(12):1778-1783. doi:10.1093/cid/cis307.

39. Sundaram ME, McClure DL, Vanwormer JJ, Friedrich TC, Meece JK, Belongia EA. Influenza vaccination is not associated with detection of noninfluenza respiratory viruses in seasonal studies of influenza vaccine effectiveness. Clin Infect Dis. 2013;57(6):789-793. doi:10.1093/cid/cit379.

40. Simonsen L, Reichert TA, Viboud C, Blackwelder WC, Taylor RJ, Miller MA. Impact of influenza vaccination on seasonal mortality in the US elderly population. Arch Intern Med.

2005;165(3):265-272. doi:10.1001/archinte.165.3.265. 
41. Simonsen L, Taylor RJ, Viboud C, Miller MA, Jackson LA. Mortality benefits of influenza vaccination in elderly people: an ongoing controversy. Lancet Infect Dis. 2007;7(10):658-666. doi:10.1016/S1473-3099(07)70236-0.

42. Jefferson T, Di Pietrantonj C, Al-ansary L, et al. Vaccines for preventing influenza in the elderly. Cochrane Database Syst. 2010;2:1-32. doi:doi: 10.1002/14651858.CD004876.pub3.

43. Darvishian M, Bijlsma MJ, Hak E, van den Heuvel ER. Effectiveness of seasonal influenza vaccine in community-dwelling elderly people: A meta-analysis of test-negative design casecontrol studies. Lancet Infect Dis. 2014;14(12):1228-1239. doi:10.1016/S1473-3099(14)709600.

44. Lang PO, Mendes A, Socquet J, Assir N, Govind S, Aspinall R. Effectiveness of influenza vaccine in aging and older adults: Comprehensive analysis of the evidence. Clin Interv Aging. 2012;7:55-64. doi:10.2147/CIA.S25215.

45. Beyer WEP, McElhaney J, Smith DJ, Monto AS, Nguyen-Van-Tam JS, Osterhaus A d. Cochrane re-arranged: Support for policies to vaccinate elderly people against influenza. Vaccine. 2013;31(50):6030-6033. doi:10.1016/j.vaccine.2013.09.063.

46. DiazGranados CA, Dunning AJ, Kimmel M, et al. Efficacy of high-dose versus standard-dose influenza vaccine in older adults. N Engl J Med. 2014;371(7):635-645. doi:10.1056/NEJMoa1315727.

47. McElhaney JE, Coler RN, Baldwin SL. Immunologic correlates of protection and potential role for adjuvants to improve influenza vaccines in older adults. Expert Rev Vaccines. 2013;12(7):759-766. doi:10.1586/14760584.2013.811193.

48. Belshe RB, Gruber WC, Mendelman PM, et al. Correlates of immune protection induced by live, attenuated, cold-adapted, trivalent, intranasal influenza virus vaccine. J Infect Dis. 2000;181(3):1133-1137. doi:10.1086/315323.

49. O'Flanagan D, Cotter S, Mereckiene J. Seasonal influenza vaccination in EU / EEA, influenza season 2011-12, Vaccine European New Integrated Collaboration (VENICE ) II Consortium. September 2012- February 2013. http://venice.cineca.org/VENICE_Seasonal_Influenza_201112_1.0v.pdf. Published 2013. Accessed June 1, 2016.

50. Fleming DM, Crovari $\mathrm{P}, \mathrm{Wahn} \mathrm{U}$, et al. Comparison of the efficacy and safety of live attenuated 
cold-adapted influenza vaccine, trivalent, with trivalent inactivated influenza virus vaccine in children and adolescents with asthma. Pediatr Infect Dis J. 2006;25(10):860-869. doi:10.1097/01.inf.0000237797.14283.cf.

51. Cates CJ, Jefferson TO, Rowe BH. Vaccines for preventing influenza in people with asthma. Cochrane Database Syst Rev. 2008;(2). doi:10.1002/14651858.CD000364.pub3.

52. Lyn-Cook R, Halm EA, Wisnivesky JP. Determinants of adherence to influenza vaccination among inner-city adults with persistent asthma. Prim Care Respir J. 2007;16(4):229-235. doi:10.3132/pcrj.2007.00056.

53. Lambert LC, Fauci AS. Influenza vaccines for the future. N Eng/ J Med. 2010;363(21):20362044. doi:10.1056/NEJMra1002842.

54. Dunning J, Openshaw PJM. Impact of the 2009 influenza pandemic. Thorax. 2010;65(6):471472. doi:10.1136/thx.2009.133728.

55. Treanor JJ, Campbell JD, Zangwill KM, Rowe T, Wolff M. Safety and immunogenicity of an inactivated subvirion influenza A (H5N1) vaccine. N Engl J Med. 2006;354:1343-1351. doi:10.1056/NEJMoa055778.

56. McCullers JA, Huber VC. Correlates of vaccine protection from influenza and its complications. Hum Vaccines Immunother. 2012;8(1):34-44. doi:10.4161/hv.8.1.18214.

57. Trombetta C, Perini D, Mather S, Temperton N, Montomoli E. Overview of Serological Techniques for Influenza Vaccine Evaluation: Past, Present and Future. Vaccines. 2014;2(4):707-734. doi:10.3390/vaccines2040707.

58. Barria MI, Garrido JL, Stein C, et al. Localized mucosal response to intranasal live attenuated influenza vaccine in adults. J Infect Dis. 2013;207(1):115-124. doi:10.1093/infdis/jis641.

59. Wilkinson TM a., Li CK., Chui CSC, et al. Preexisting influenza-specific CD4+ T cells correlate with disease protection against influenza challenge in humans. Nat Med. 2012;18(2):276-282. doi:10.1038/nm.2612.

60. Sridhar S, Begom S, Bermingham A, et al. Cellular immune correlates of protection against symptomatic pandemic influenza. Nat Med. 2013;19(10):1305-1312. doi:10.1038/nm.3350.

61. Thomas PG, Keating R, Hulse-Post DJ, Doherty PC. Cell-mediated protection in influenza infection. Emerg Infect Dis. 2006;12(1):48-54. doi:10.3201/eid1201.051237. 
62. McElhaney JE, Xie D, Hager WD, et al. T cell responses are better correlates of vaccine protection in the elderly. J Immunol. 2006;176(10):6333-6339. doi:10.4049/jimmunol.176.10.6333.

63. Bright RA, Medina MJ, Xu X, et al. Incidence of adamantane resistance among influenza $\mathrm{A}$ (H3N2) viruses isolated worldwide from 1994 to 2005: A cause for concern. Lancet. 2005;366(9492):1175-1181. doi:10.1016/S0140-6736(05)67338-2.

64. Dharan NJ, Gubareva L V, Meyer JJ, et al. Infections with oseltamivir-resistant influenza A(H1N1) virus in the United States. JAMA. 2009;301(10):1034-1041. doi:10.1001/jama.2009.294.

65. Tetsutani K, Ishii KJ. Adjuvants in influenza vaccines. Vaccine. 2012;30(52):7658-7661. doi:10.1016/j.vaccine.2012.10.007.

66. Goff PH, Hayashi T, Martínez-Gil L, et al. Synthetic Toll-Like Receptor 4 (TLR4) and TLR7 Ligands as Influenza Virus Vaccine Adjuvants Induce Rapid, Sustained, and Broadly Protective Responses. J Virol. 2015;89(6):3221-3235. doi:10.1128/JVI.03337-14.

67. Jegerlehner A, Schmitz N, Storni T, Bachmann MF. Influenza A vaccine based on the extracellular domain of M2: weak protection mediated via antibody-dependent NK cell activity. J Immunol. 2004;172(9):5598-5605. doi:10.4049/jimmunol.172.9.5598.

68. El Bakkouri K, Descamps F, De Filette M, et al. Universal vaccine based on ectodomain of matrix protein 2 of influenza A: Fc receptors and alveolar macrophages mediate protection. $J$ Immunol. 2011;186(2):1022-1031. doi:10.1016/j.ymed.2011.08.035.

69. Staneková Z, Varečková E. Conserved epitopes of influenza A virus inducing protective immunity and their prospects for universal vaccine development. Virol J. 2010;7:351. doi:10.1186/1743-422X-7-351.

70. Wacheck V, Egorov A, Groiss F, et al. A novel type of influenza vaccine: safety and immunogenicity of replication-deficient influenza virus created by deletion of the interferon antagonist NS1. J Infect Dis. 2010;201(3):354-362. doi:10.1086/649428.

71. Xiang K, Ying G, Yan Z, et al. Progress on adenovirus-vectored universal influenza vaccines. Hum Vaccines Immunother. 2015;11(5):1209-1222. doi:10.1080/21645515.2015.1016674.

72. Jha A, Jarvis H, Fraser C, Openshaw PJ. Respiratory Syncytial Virus. Eur Respir Soc Monogr. 
2016;72:84-109. doi:10.1183/2312508X.10010315.

73. Nair H, Nokes DJ, Gessner BD, et al. Global burden of acute lower respiratory infections due to respiratory syncytial virus in young children: a systematic review and meta-analysis. Lancet. 2010;375(9725):1545-1555. doi:10.1016/S0140-6736(10)60206-1.

74. Meissner HC, Ingelfinger JR, Meissner HC. Viral Bronchiolitis in Children. N Engl J Med. 2016;374(1):62-72. doi:10.1056/NEJMra1413456.

75. Kim HW, Canchola JG, Brandt CD, et al. Respiratory syncytial virus disease in infants despite prior administration of antigenic inactivated vaccine. Am J Epidemiol. 1969;89(4):422-434.

76. Fulginiti VA, Eller JJ, Joyner JW, et al. Respiratory virus immunization. Am J Epidemiol. $1969 ; 89(4): 435-448$.

77. De Swart RL, Kuiken T, Timmerman HH, et al. Immunization of macaques with formalininactivated respiratory syncytial virus (RSV) induces interleukin-13-associated hypersensitivity to subsequent RSV infection. J Virol. 2002;76(22):11561-11569. doi:10.1128/JVI.76.22.1156111569.2002.

78. Acosta P, Caballero M, Polacka P. Brief History and Characterization of Enhanced Respiratory Syncytial. Clin vaccine Immunol. 2016;23(3):189-195. doi:10.1128/CVI.00609-15.Editor.

79. Loebbermann J, Durant L, Thornton H, Johansson C, Openshaw PJ. Defective immunoregulation in RSV vaccine-augmented viral lung disease restored by selective chemoattraction of regulatory T cells. Proc Natl Acad Sci U S A. 2013;110(8):2987-2992. doi:10.1073/pnas.1217580110.

80. Guvenel AK, Chiu C, Openshaw PJ. Current concepts and progress in RSV vaccine development. Expert Rev Vaccines. 2014;13(3):333-344. doi:10.1586/14760584.2014.878653.

81. Connors M, Collins PL, Firestone CY, Murphy BR. Respiratory syncytial virus (RSV) F, G, M2 (22K), and N proteins each induce resistance to RSV challenge, but resistance induced by $\mathrm{M} 2$ and N proteins is relatively short-lived. J Virol. 1991;65(3):1634-1637.

82. McLellan JS, Chen M, Leung S, et al. Structure of RSV fusion glycoprotein trimer bound to a prefusion-specific neutralizing antibody. Science. 2013;340(6136):1113-1117. doi:10.1126/science.1234914.

83. Bukreyev A, Yang L, Fricke J, et al. The secreted form of respiratory syncytial virus G 
glycoprotein helps the virus evade antibody-mediated restriction of replication by acting as an antigen decoy and through effects on Fc receptor-bearing leukocytes. J Virol. 2008;82(24):12191-12204. doi:10.1128/JVI.01604-08.

84. Chirkova T, Boyoglu-Barnum S, Gaston K a, et al. Respiratory Syncytial Virus G Protein CX3C Motif Impairs Human Airway Epithelial and Immune Cell Responses. J Virol. 2013;87(24):13466-13479. doi:10.1128/JVI.01741-13.

85. Jorquera P, Oakley K, Powell T, Palath N, Boyd J, Tripp R. Layer-By-Layer Nanoparticle Vaccines Carrying the G Protein CX3C Motif Protect against RSV Infection and Disease. Vaccines. 2015;3(4):829-849. doi:10.3390/vaccines3040829.

86. McLellan JS, Chen M, Joyce MG, et al. Structure-based design of a fusion glycoprotein vaccine for respiratory syncytial virus. Science (80- ). 2013;342(6158):592-598. doi:10.1126/science.1243283.

87. Jozwik A, Habibi MS, Paras A, et al. RSV-specific airway resident memory CD8+ T cells and differential disease severity after experimental human infection. Nat Commun. 2015;6:10224. doi:10.1038/ncomms10224.

88. The IMpact-RSV Study Group. Palivizumab, a humanized respiratory syncytial virus monoclonal antibody, reduces hospitalization from respiratory syncytial virus infection in high-risk infants. Pediatrics. 1998;102(3 Pt 1):531-537.

89. Blanken MO, Rovers MM, Molenaar JM, et al. Respiratory syncytial virus and recurrent wheeze in healthy preterm infants. N Engl J Med. 2013;368(19):1791-1799.

90. Committee on Infectious Diseases and Bronchiolitis Guidelines. Updated guidance for palivizumab prophylaxis among infants and young children at increased risk of hospitalization for respiratory syncytial virus infection. Pediatrics. 2014;134(2):415-420. doi:10.1542/peds.2014-1665.

91. Ralston S, Lieberthal A, Meissner H, et al. Clinical Practice Guideline : The Diagnosis , Management, and Prevention of Bronchiolitis. Pediatrics. 2014;134:e1474-e1502. doi:10.1542/peds.2014-2742.

92. O'Brien KL, Chandran A, Weatherholtz R, et al. Efficacy of motavizumab for the prevention of respiratory syncytial virus disease in healthy Native American infants: A phase 3 randomised 
double-blind placebo-controlled trial. Lancet Infect Dis. 2015;15(December):1398-1408. doi:10.1016/S1473-3099(15)00247-9.

93. Malkin E, Yogev R, Abughali N, et al. Safety and immunogenicity of a live attenuated RSV vaccine in healthy RSV-seronegative children 5 to 24 months of age. PLoS One. 2013;8(10):e77104. doi:10.1371/journal.pone.0077104.

94. Polack FP. The changing landscape of respiratory syncytial virus. Vaccine. 2015:4-9. doi:10.1016/j.vaccine.2015.06.119.

95. Saso A, Kampmann B. Vaccination against respiratory syncytial virus in pregnancy: a suitable tool to combat global infant morbidity and mortality? Lancet Infect Dis. 2016;16(8):e153e163. doi:10.1016/S1473-3099(16)00119-5.

96. Habibi MS, Jozwik A, Makris S, et al. Impaired Antibody-mediated Protection and Defective IgA B-Cell Memory in Experimental Infection of Adults with Respiratory Syncytial Virus. Am J Respir Crit Care Med. 2015;191(9):1040-1049. doi:10.1164/rccm.201412-22560C.

97. PATH. Vaccine development - Vaccine Development Global Program. http://sites.path.org/vaccinedevelopment/respiratory-syncytial-virus-rsv/vaccinedevelopment/. Accessed May 19, 2016.

98. Munoz FM. Parainfluenza viruses in children. UpToDate. https://www.uptodate.com/contents/parainfluenza-viruses-in-children. Published 2016. Accessed May 20, 2016.

99. Lehners N, Tabatabai J, Prifert C, et al. Long-Term Shedding of Influenza Virus, Parainfluenza Virus, Respiratory Syncytial Virus and Nosocomial Epidemiology in Patients with Hematological Disorders. PLoS One. 2016;11(2):e0148258.

doi:10.1371/journal.pone.0148258.

100. Cohen AL, Sahr PK, Treurnicht F, et al. Parainfluenza Virus Infection Among Human Immunodeficiency Virus (HIV)-Infected and HIV-Uninfected Children and Adults Hospitalized for Severe Acute Respiratory Illness in South Africa, 2009-2014. Open Forum Infect Dis. 2015;2(4):ofv139. doi:10.1093/ofid/ofv139.

101. Parrott R, Vargosko A, Kim H, Bell J, Chanock R. Acute respiratory diseases of viral etiology. III. parainfluenza. Myxoviruses. Am J Public Health Nations Health. 1962;52:907-917. 
102. Glezen WP, Frank a L, Taber LH, Kasel J a. Parainfluenza virus type 3: seasonality and risk of infection and reinfection in young children. J Infect Dis. 1984;150(6):851-7.

103. Schmidt A. Progress in Respiratory Virus Vaccine Development. Semin Respir Crit Care Med. 2011;32(4):527-540. doi:10.1055/s-0031-1283289.

104. Karron RA, Belshe RB, Wright PF, et al. A live human parainfluenza type 3 virus vaccine is attenuated and immunogenic in young infants. Pediatr Infect Dis J. 2003;22(5):394-405. doi:10.1097/01.inf.0000066244.31769.83.

105. Karron RA, Wright PF, Newman FK, et al. A live human parainfluenza type 3 virus vaccine is attenuated and immunogenic in healthy infants and children. J Infect Dis. 1995;172(6):14451450.

106. Madhi SA, Cutland C, Zhu Y, et al. Transmissibility, infectivity and immunogenicity of a live human parainfluenza type 3 virus vaccine (HPIV3cp45) among susceptible infants and toddlers. Vaccine. 2006;24(13):2432-2439. doi:10.1016/j.vaccine.2005.12.002.

107. Belshe RB, Newman FK, Tsai TF, et al. Phase 2 evaluation of parainfluenza type 3 cold passage mutant 45 live attenuated vaccine in healthy children 6-18 months old. J Infect Dis. 2004;189(3):462-470. doi:10.1086/381184.

108. Schmidt AC, Schaap-Nutt A, Bartlett EJ, et al. Progress in the development of human parainfluenza virus vaccines. Expert Rev Respir Med. 2011;5(4):515-526. doi:10.1586/ers.11.32.

109. Englund J a., Karron R a., Cunningham CK, et al. Safety and infectivity of two doses of liveattenuated recombinant cold-passaged human parainfluenza type 3 virus vaccine rHPIV3cp45 in HPIV3-seronegative young children. Vaccine. 2013;31(48):5706-5712. doi:10.1016/j.vaccine.2013.09.046.

110. van Wyke Coelingh KL, Winter CC, Tierney EL, London WT, Murphy BR. Attenuation of bovine parainfluenza virus type 3 in nonhuman primates and its ability to confer immunity to human parainfluenza virus type 3 challenge. J Infect Dis. 1988;157(4):655-662.

111. Greenberg DP, Walker RE, Lee M-S, et al. A bovine parainfluenza virus type 3 vaccine is safe and immunogenic in early infancy. J Infect Dis. 2005;191(7):1116-1122. doi:10.1086/428092.

112. Karron RA, Thumar B, Schappell E, et al. Evaluation of two chimeric bovine-human 
parainfluenza virus type 3 vaccines in infants and young children. Vaccine. 2012;30(26):39753981. doi:10.1016/j.vaccine.2011.12.022.

113. Karron RA, San Mateo J, Thumar B, et al. Evaluation of a Live-Attenuated Human Parainfluenza Type 1 Vaccine in Adults and Children. J Pediatric Infect Dis Soc. 2015;4(4):143146. doi:10.1093/jpids/piu104.

114. Schmidt AC, Auliffe JMMC, Murphy BR, Collins PL. Recombinant Bovine / Human Parainfluenza Virus Type 3 ( B / HPIV3 ) Expressing the Respiratory Syncytial Virus ( RSV ) G and F Proteins Can Be Used To Achieve Simultaneous Mucosal Immunization against RSV and HPIV3. 2001;75(10):4594-4603. doi:10.1128/JVI.75.10.4594.

115. Bernstein DI, Malkin E, Abughali N, Falloon J, Yi T, Dubovsky F. Phase 1 study of the safety and immunogenicity of a live, attenuated respiratory syncytial virus and parainfluenza virus type 3 vaccine in seronegative children. Pediatr Infect Dis J. 2012;31(2):109-114.

doi:10.1097/INF.0b013e31823386f1.

116. Rowe WP, Huebner RJ, Gilmore LK, Parrott RH, Ward G. Isolation of a Cytopathogenic Agent from Human Adenoids Undergoing Spontaneous Degeneration in Tissue Culture. Proc Soc Exp Biol Med. 1953;84(3):570-573. doi:10.3181/00379727-84-20714.

117. Potter RN, Cantrell JA, Mallak CT, Gaydos JC. Adenovirusassociated deaths in us military during postvaccination period, 1999-2010. Emerg Infect Dis. 2012;18(3):507-509. doi:10.3201/eid1803.111238.

118. Echavarría M. Adenoviruses in immunocompromised hosts. Clin Microbiol Rev. 2008;21(4):704-715. doi:10.1128/CMR.00052-07.

119. Hilleman MR, Gauld RL, Butler RL, et al. Appraisal of occurrence of adenovirus-caused respiratory illness in military populations. Am J Hyg. 1957;66(1):29-41.

120. Gray G, Goswami P, Malasig M, et al. Adult adenovirus infections: Loss of orphaned vaccines precipitates military respiratory disease epidemics. Clin Infect Dis. 2000;31(3):663-670. doi:10.1086/313999.

121. Kuschner RA, Russell KL, Abuja M, et al. A phase 3, randomized, double-blind, placebocontrolled study of the safety and efficacy of the live, oral adenovirus type 4 and type 7 vaccine, in U.S. military recruits. Vaccine. 2013;31(28):2963-2971. 
doi:10.1016/j.vaccine.2013.04.035.

122. Hoke $\mathrm{CH}$, Hawksworth $\mathrm{A}$, Snyder $\mathrm{CE}$. Initial assessment of impact of adenovirus type 4 and type 7 vaccine on febrile respiratory illness and virus transmission in military basic trainees, March 2012. Med Surv Mon Rep. 2012;19(3):2-5. 